\title{
Coexistent corneal disease and glaucoma managed by either drainage surgery and subsequent keratoplasty or combined drainage surgery and penetrating keratoplasty
}

\author{
Colin M Kirkness, Arthur D McG Steele, Linda A Ficker, Noel S C Rice
}

\begin{abstract}
The results of penetrating keratoplasty following trabeculectomy in $\mathbf{2 6}$ eyes where there was coexistent corneal disease and glaucoma are presented. Patients were aged $16-80$ years at the time of drainage surgery (mean $=51$ years) and there was a mean of 33.5 months between trabeculectomy and keratoplasty. The mean pressure fell from $35.3 \mathrm{~mm} \mathrm{Hg}$ prior to trabeculectomy to $14.9 \mathrm{~mm} \mathrm{Hg}$ at the time of keratoplasty and $20 \mathrm{~mm} \mathrm{Hg} 12$ months after keratoplasty. There was a 0.45 probability of maintaining normal intraocular pressure with medication at 5 years after keratoplasty; and a similar graft survival probability. The probability of maintaining both a clear graft and a normal pressure was only 0.27 at 5 years. In another 22 eyes combined trabeculectomy and penetrating keratoplasty was performed. Patients' ages ranged from 21-82 years (mean 55 ) at surgery, and $73 \%$ were aphakic. The intraocular pressure dropped from a mean of $28.9 \mathrm{~mm} \mathrm{Hg}$ preoperatively to $14 \mathrm{~mm} \mathrm{Hg}$ at 12 months. There was a 5 year probability of 0.7 of maintaining a clear graft but if both a clear graft and normal intraocular pressure are considered then the probability falls to 0.5 at 5 years. The hazard ratio for intraocular pressure control and graft survival between the two groups suggests that combined surgery may offer a better prognosis.
\end{abstract}

The combination of raised intraocular pressure (IOP) and corneal opacification presents ophthalmologists with difficult management decisions. The association is not necessarily uncommon since bullous keratopathy may often be seen in association with aphakic or pseudophakic glaucoma. ${ }^{1-16}$ Indeed the trauma of the initial cataract surgery may be a common aetiological factor.

In the situation where the corneal disease leads to permanent corneal scarring or opacification then visual rehabilitation by penetrating keratoplasty may be hampered by the worsening of the glaucoma even rendering medical control impossible. In other circumstances corneal opacification may develop following planned trabeculectomy rendering keratoplasty necessary if the patient is to achieve useful vision. Kirkness and Moshegov ${ }^{17}$ pointed out that control of IOP usually deteriorated after keratoplasty in glaucomatous eyes but they did demonstrate that in some eyes the control surprisingly improved at least temporarily.
Opinions on the management of eyes with glaucoma and corneal disease have varied from the suggestion that penetrating keratoplasty is contraindicated ${ }^{18}$ to the advice that penetrating keratoplasty may be undertaken once the IOP has been controlled surgically. ${ }^{19}$ The trauma of graft surgery and the associated inflammation may however predispose to bleb fibrosis and failure so prejudicing control of IOP.

Despite the longstanding recognition of this problem, there is little substantive work published to support these anecdotal assertions. Since sequential surgery may not always be desirable and since it had at the time of commencement of this study an unproved prognosis there appeared to be a place for a combined procedure for penetrating keratoplasty and trabeculectomy. Combined cataract surgery and trabeculectomy, for instance, have an established a good prognosis with relatively low rates of complications. ${ }^{20}$ The surgery involved in keratoplasty is more complex than cataract surgery and the results of combined procedures might well be expected to be worse as well as having more important complications. There is little information on combined keratoplasty and trabeculectomy apart from Insler et $a l^{21}$ who reported seven cases with short follow-up but encouraging results. Barraquer et $a l^{22}$ reported anecdotally similar encouraging results in a small number of patients.

More advanced cases of glaucoma which have already undergone trabeculectomy and failed or in which there is extensive anterior segment disorganisation and conjunctival scarring may be considered more suitable for insertion of silicone drainage tubing. ${ }^{23}$

The results from within the corneal clinic of Moorfields Eye Hospital, both from sequential surgery and from combined penetrating keratoplasty and glaucoma procedures, are presented in an effort to establish the likely success of the procedures from the point of view of graft survival, control of IOP, and visual acuity and also to try to establish the likely important complications of the surgery.

Field testing in this group of patients with corneal scarring and possibly additional cataract or aphakia is notoriously unreliable and changes in scotomata are often difficult to interpret. As a result rather more emphasis must sometimes be placed on the IOP than might be considered ideal. It must be stressed that these two series do not represent any attempt at randomisation. The surgery in each case was performed because it was deemed more appropriate by the surgeon in 
charge. As such there will inevitably be bias. Comparisons between the two groups must be interpreted with caution.

\section{Patients and methods}

Patients were identified from case notes and a database of patients attending the Corneal Clinic, Moorfields Eye Hospital. Since 1987 this work has been prospective but data acquired before this time were entered retrospectively from the case notes.

From 1975 to 198926 patients (26 eyes) were identified undergoing drainage surgery followed by keratoplasty - group A. No case was bilateral. Only cases in which keratoplasty was performed following drainage surgery were included. Eyes undergoing keratoplasty after drainage surgery where the drainage procedure had already failed at the time of keratoplasty were excluded from the study as were eyes which had already had combined drainage procedures and keratoplasty, that is any case of post-keratoplasty glaucoma was excluded.

In 24 cases there was a trabeculectomy and two eyes had silicone drainage tubes inserted for control of IOP. The mean follow-up was 94 months (SEM 19.7 - that is \pm 2 standard errors of the mean) and the mean interval between drainage and keratoplasty was 33.5 months (SEM 10.7). There is a minimum follow-up of 6 months on each patient following keratoplasty (in fact all have been followed for more than 12 months). Patients were aged from 6-80 years at the time of drainage, mean 51.3 (SEM 7.22), median 52.

Twenty two patients underwent combined drainage surgery and keratoplasty - group B. Patients' ages ranged from 21-82 years at the time of surgery, mean 54.8(SEM 8.4), median 62. Follow-up is from 6 months to 8 years, mean 34 (SEM 11.5) months. All eyes had glaucoma, with poorly controlled raised IOP at the time of combined surgery.

The indications for keratoplasty in group A are shown in Fig 1. In group A two patients had a primary glaucoma leading to corneal endothelial failure. Anterior chamber cleavage syndromes also figure largely $(n=5)$ but otherwise the disease categories reflect a spectrum of the usual groups at risk of developing postkeratoplasty glaucoma.

The indications for trabeculectomy in both groups were failure to control IOP adequately or to prevent field loss on (tolerable) medical therapy. Silicone drainage tube surgery was indicated where there had been a failure of

Figure 1 The indications for keratoplasty for patients in groups $A$ and $B$. $A C S=$ anterior chamber cleavage syndrome; $H S K=$ herpes simplex keratitis; $P B K=$ pseudophakic bullous keratopathy; $A B K=$ aphakic bullous

keratopathy; CSG = chronic simple glaucoma; $A C A G=$ acute closed angle glaucoma.

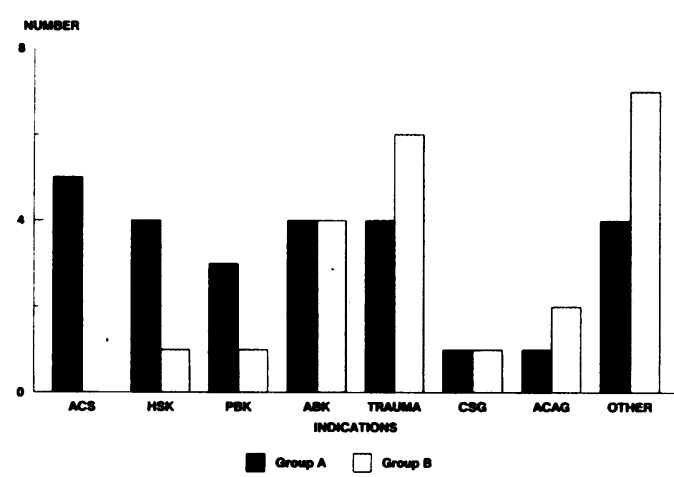

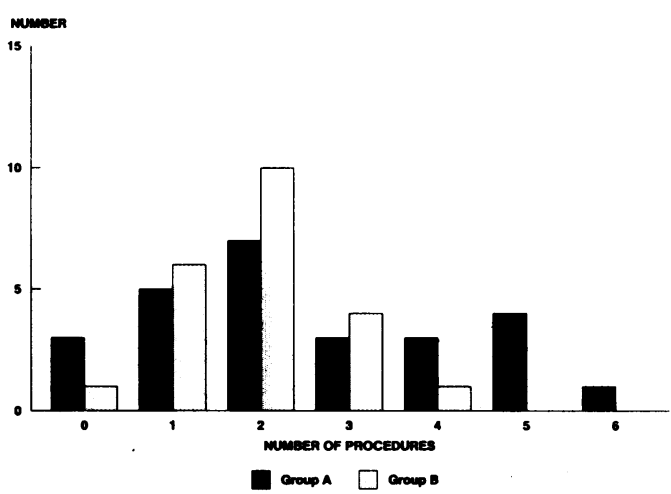

Figure 2 The number of previous intraocular procedures prior to drainage surgery, in group $A$ ( $\square$ ) and prior to combined keratoplasty and drainage surgery in group $B(\square)$.

conventional trabeculectomy to control IOP. Control of IOP was judged successful if the IOP was less than $21 \mathrm{~mm} \mathrm{Hg}$ and partially successful if additional medical therapy was necessary to control the IOP; failure was surmised when it was not controlled below $21 \mathrm{~mm} \mathrm{Hg}$ on maximum tolerable medication. If there was obvious progression of field loss or disc cupping, despite normal IOP, this was also considered to be failure.

Eight of the 26 eyes in group A had undergone previous glaucoma surgery, with eight drainage procedures. Three of these eyes had undergone both trabeculectomy and cyclocryotherapy. Six eyes had had more than one procedure. The mean number of intraocular procedures of any type, was 2.6 (SEM 0.7) (Fig 2). In addition to glaucoma surgery a number of the eyes had had cataract surgery; 10 had had intracapsular extraction, including three with intraocular lens implant; two had had extracapsular extraction and one had had cataract surgery between trabeculectomy and keratoplasty. Fifteen of the eyes were phakic at the time of trabeculectomy and the remainder had had a variety of cataract procedures as shown in Fig 3. Although 14 eyes were phakic at the time of keratoplasty, only five remained phakic throughout the study. Eight had combined cataract extraction and keratoplasty and a further one had cataract surgery following keratoplasty.

The indications for penetrating keratoplasty in group B were also varied (Fig 1). Most eyes in group B had suffered anterior segment disorganisation from cataract surgery, trauma, or

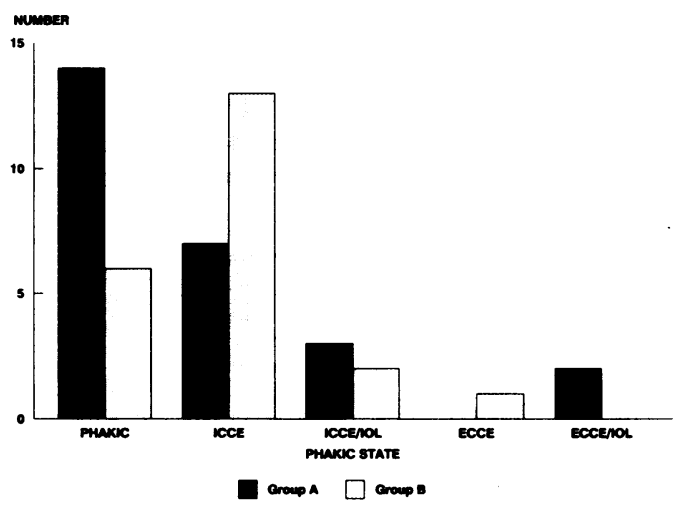

Figure 3 The phakic state at the time of keratoplasty for groups $A$ and $B$. (ICCE = intracapsular cataract extraction; $I O L=$ intraocular lens; $E C C E=$ extracapsular cataract extraction.) 
Figure 4 The amounts of synechial angle closure seen in groups $A$ and $B$. (ICCE $=$ intracapsular cataract extraction; $I O L=$ intraocular lens; $E C C E=$ extracapsular cataract extraction.)

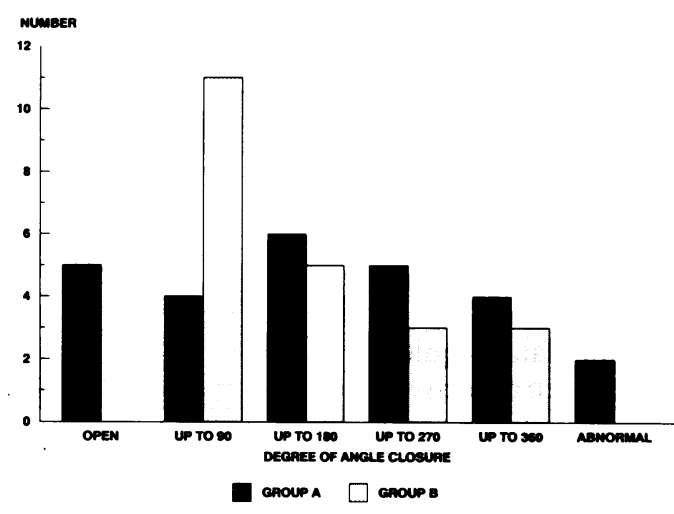

corneal perforation but in four the glaucoma was secondary to inflammatory conditions such as herpes simplex keratitis or interstitial keratitis. Only one eye had had no previous surgery while the rest had from one to four previous intraocular procedures, mean 1.9 (SEM 0.4), prior to this surgery. Six eyes were still phakic at the time of surgery, 13 had had intracapsular cataract extraction, and the rest had had an extracapsular extraction (Fig 3). Seven of the 22 eyes in group B had had previous drainage procedures, all trabeculectomies, but in one eye a cyclodialysis had been performed in addition.

Full and accurate documentation of the angle is often difficult in these eyes and assessment after keratoplasty may be misleading. An attempt was made to estimate angle closure by quadrants retrospectively. In group A some degree of angle closure by anterior synechiae was present in $70 \%$ and $12 \%$ had complete angle closure; while in group B in two eyes the angle was completely and widely open; in one it was not possible to assess the angle owing to the degree of corneal opacification; in all others there was some degree of peripheral anterior synechiae ranging from occlusion in one quadrant to total angle obliteration (Fig 4).

All of the eyes might have been considered to have had relatively abnormal or scarred conjunctiva. Scarring was attributable to previous surgery which involved the conjunctiva or to ocular surface disease.

None of the patients were on long term topical steroid therapy.

Eleven of the eyes in group A required some medication to control IOP between the trabeculectomy and the keratoplasty.

\section{THE SURGICAL TECHNIQUE - FOR COMBINED} PROCEDURE

Prior to the keratoplasty a standard trabeculectomy was begun with either a limbus or a fornix

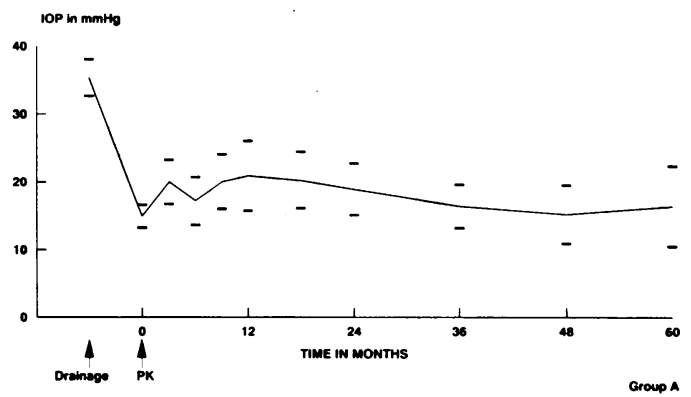

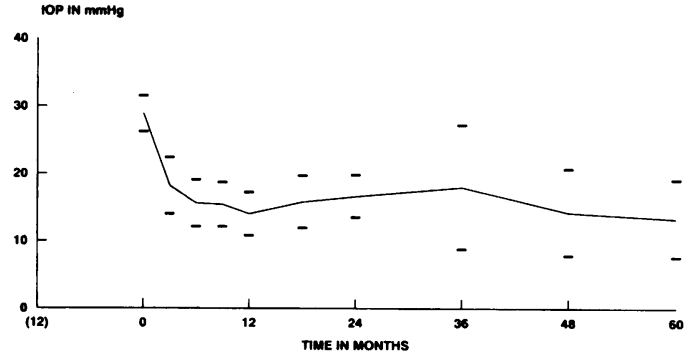

Figure $5 B$ Group B: the mean intraocular pressures with time; means are shown (SD 95\% confidence interval).

based flap. A scleral flap was raised and the block for excision marked. The procedure was halted at this stage.

A standard penetrating keratoplasty was then performed with anterior vitrectomy, removal of implant, etc being performed as necessary. Once this was complete and the wound assured to be watertight the scleral block was excised and the trabeculectomy completed in the usual fashion with $10 / 0$ nylon to the scleral flap and $8 / 0$ virgin silk to the conjunctiva.

Survival probabilities and hazard ratios were calculated according to the methods of Machin and Gardner. ${ }^{24}$

\section{Results}

\section{GROUP A}

The mean IOP fell from $35 \cdot 3$ (SEM 2.6) $\mathrm{mm} \mathrm{Hg}$ prior to trabeculectomy to $14.9($ SEM $1 \cdot 6) \mathrm{mm} \mathrm{Hg}$ at the time of keratoplasty. These results and the subsequent mean IOPs are shown in Fig 5A; this includes those of patients taking additional antiglaucoma medication where necessary. (Once a further drainage procedure was undertaken to control IOP in an eye, the IOP is no longer considered in this review.)

The IOP failed to be controlled without medication from within 1 week of keratoplasty to 45 months (50\% in under 9 months) and with additional antiglaucoma medication from 10 days to 6 years. The survival probability had fallen to 0.5 between 32 and 45 months. The survival curves for these parameters are shown in Figs 6 and 7.

At the time of this review 12 eyes had failed to have adequately controlled IOP, six are controlled with additional medical therapy and eight are successfully controlled with no antiglaucoma therapy. The amount of antiglaucoma medication required after keratoplasty is shown in Fig

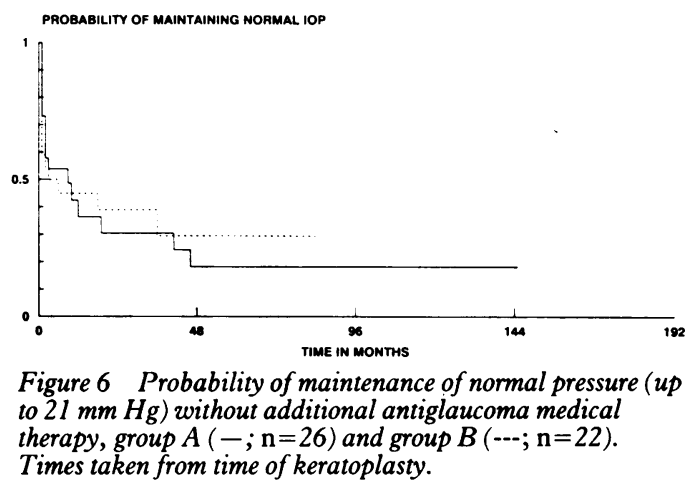

Figure 5A Group A: the mean intraocular pressures with time; means are shown SD $95 \%$ confidence interval). Note the discontinuity of scale between drainage surgery and keratoplasty. 
Figure 7 Probability of maintenance of normal pressure (up to $21 \mathrm{~mm} \mathrm{Hg}$ ) with additional antiglaucoma medical therapy where necessary group $A(-; \mathrm{n}=26)$ and group $B(---; n=22)$. Times taken from time of keratoplasty.

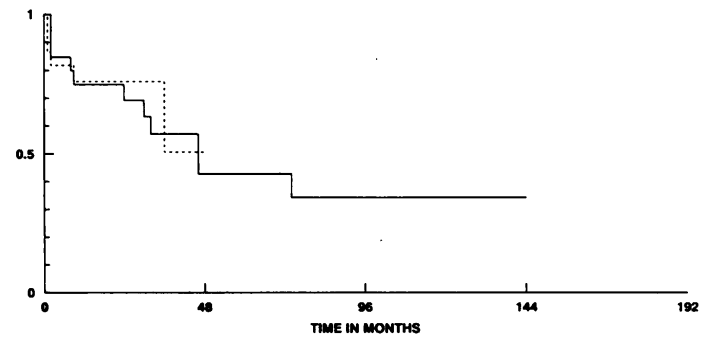

8. It may be seen that five patients are taking more medication after keratoplasty than they were taking before and it might be speculated that these eyes are also likely to fail to be controlled in due course. The range of antiglaucoma medications used reflects nearly all commonly available medications but carbonic anhydrase inhibitors, beta blockers, and pilocarpine were the most widely used.

Where control of IOP was lost, two eyes did not undergo further surgery since the visual function was so poor, five eyes underwent further trabeculectomy, two eyes had silicone tubes inserted, and three had cyclocryotherapy. Two of the trabeculectomies failed. One had a tube inserted which maintains successful control at the time of this review, and in the other eye subsequent cyclocryotherapy failed. One of the eyes receiving cyclocryotherapy had a tube inserted but this eye developed prolonged hypotony and is phthisical. Thus of the original 12 failures six are currently controlled following further procedure(s).

Failure of IOP control occurred in seven of the eight patients who had undergone previous procedures for control of IOP. Repeat trabeculectomy being followed by keratoplasty must be considered to carry a significantly worse prognosis - relative risk of failure $3 \cdot 2,95 \%$ confidence interval 1.4-6.9, compared with single trabeculectomy and keratoplasty

Graft survival is shown in Fig 9. The survival of grafts in this group of patients is clearly poor with $50 \%$ failing at about 4 years. The causes of graft failure were rejections $(n=7)$, recurrence of herpes keratitis $(n=2)$, and recurrence of epithelial downgrowth $(n=1)$. One graft each failed after retinal detachment and application of cyclocryotherapy.

The maintenance of both a clear graft and controlled IOP is (obviously) also poor but in fact closely parallels both previously described graphs suggesting that graft failure and loss of IOP control are in fact related (Fig 10).

Complications directly related to the surgery
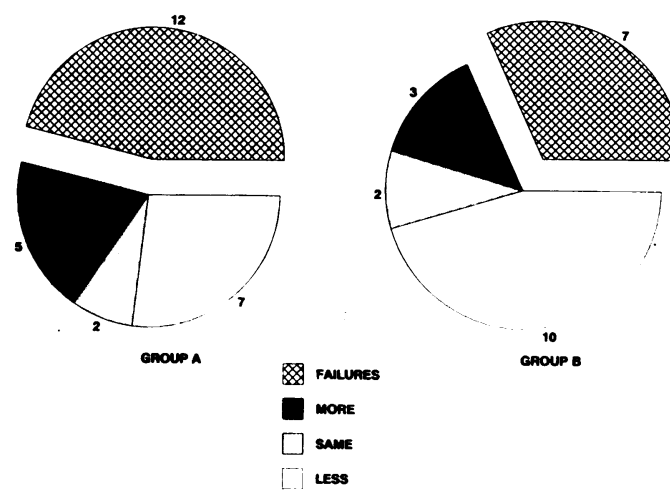

Figure 8 The need for additional medical antiglaucoma theraf
groups $A$ and $B$.

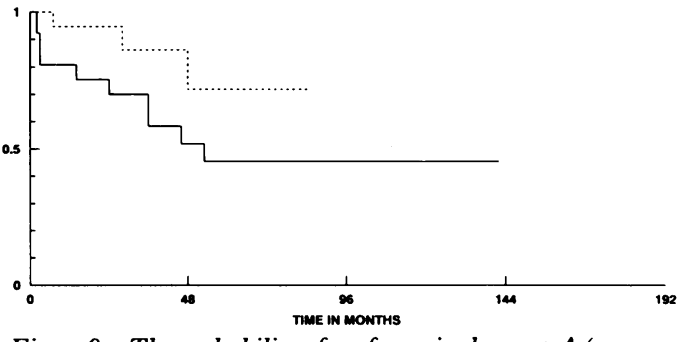

Figure 9 The probability of graft survival, group $A(-; \mathrm{n}=$ 26) and group $B(---;=22)$. Times taken from time of keratoplasty.

were seen infrequently. Three eyes had cystoid macular oedema which probably related to previous cataract surgery. One developed a retinal detachment following intracapsular extraction which had preceded keratoplasty. One eye developed microbial keratitis in the graft and one eye which had a tube in situ developed persistent hypotony after keratoplasty necessitating removal of the tube. This eye had already suffered graft failure from rejection.

The visual results are shown in Fig 11A. In many cases the visual potential was already reduced because of the preceding glaucoma, amblyopia, or other ocular disease. In seven eyes failure to control the IOP adequately remained the major cause of visual loss in the postkeratoplasty period. In five others vision was lost as a result of cyclocryotherapy, retinal detachment, epithelial downgrowth, diabetic retinopathy, and recurrence of herpes simplex keratitis, respectively. No relationship could be demonstrated between the outcome and the degree of peripheral anterior synechiae, lens state, or interval between drainage and keratoplasty.

\section{GROUP B}

The mean IOP preoperatively was $28 \cdot 9$ (SEM $3 \cdot 5$ ) $\mathrm{mm} \mathrm{Hg}$. This fell to $18 \cdot 2$ (SEM 4) $\mathrm{mm} \mathrm{Hg}$ at 3 months and $15 \cdot 6$ (SEM 3.2) $\mathrm{mm} \mathrm{Hg}$ at 6 months (Fig 5B).

At the time of this review, eight eyes are controlled successfully without additional medical therapy and a further seven with additional therapy. The survival curves for pressure control are shown in Figs 6 and 7. From these it can be seen that $50 \%$ are anticipated to require medical therapy within 6 months and $50 \%$ have failed completely by 3 years. Two eyes went on to have further trabeculectomy which failed and then silicone drainage tubes were inserted; two went on to have silicone drainage

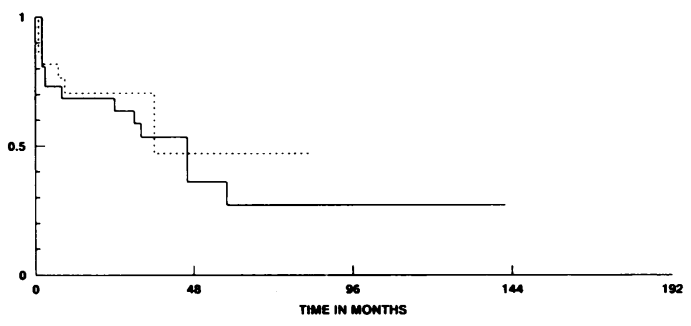

Figure 10 Probability of maintenance of normal pressure with additional antiglaucoma medical therapy where necessary and a clear graft, group $A(-; \mathrm{n}=26)$ and group $B$ $(--; \mathrm{n}=22)$. Times taken from time of keratoplasty. Normal $I O P$ up to $21 \mathrm{~mm} \mathrm{Hg}$ (with additional medical therapy where necessary). 


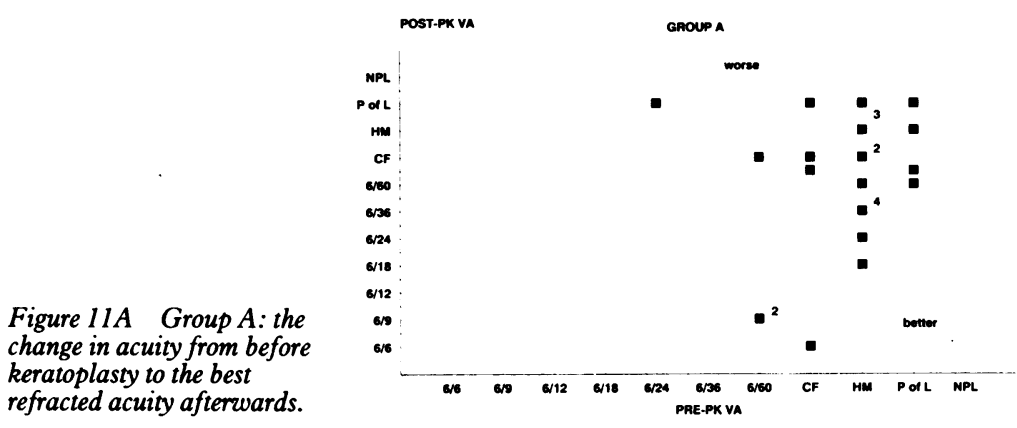

tubes inserted and one had cyclocryotherapy. The distribution of medication and failures is shown in Fig 8. Patients undergoing a repeat trabeculectomy as part of the combined procedure did not have a greater risk of failure of control of pressure, relative risk $0.86,95 \%$ confidence interval $0 \cdot 22$ to $3 \cdot 4$.

Complications directly attributable to the surgery were rare but one eye with a history of herpes simplex keratitis which underwent, in addition, an extracapsular lens extraction had a flat anterior chamber immediately postoperatively lasting several days. When the chamber reformed spontaneously approximately $120^{\circ}$ of anterior synechiae to the graft-host interface were found. No action was taken and this graft survives with well-controlled IOP and good vision 4 years later. Graft survival was moderate with a probability of survival of 0.7 at 5 years. When the maintenance of a both clear graft and normal IOP is considered the survival probability is 0.5 at 3 years (Figs 9 and 10).

Only one eye lost vision compared to preoperative levels, six remained the same and the remainder improved by variable amounts (see Fig 11B). As well as continuing optic disc damage and lack of graft clarity causing visual loss there was one instance each of cystoid macular oedema, age-related macular degeneration, retinal detachment, and optic disc ischaemia thought to be independent of the glaucoma. There was also one case of late hypotony which resulted in poor vision. All grafts which failed did so following rejection episodes.

Although not randomised the two groups may be compared statistically. The hazard ratio for maintenance of IOP control (with additional medication where necessary) at 5 years for combined versus sequential surgery is $0.40,95 \%$ confidence interval $0 \cdot 15$ to $0 \cdot 90$. This strongly suggests that sequential surgery is less successful in maintaining IOP control. Similarly the hazard ratio for maintenance of graft clarity at 5 years is $0 \cdot 4,95 \%$ confidence interval $0 \cdot 14$ to $0 \cdot 95$. This

Figure 11B Group B: the change in acuity from before keratoplasty to the best refracted acuity afterwards.

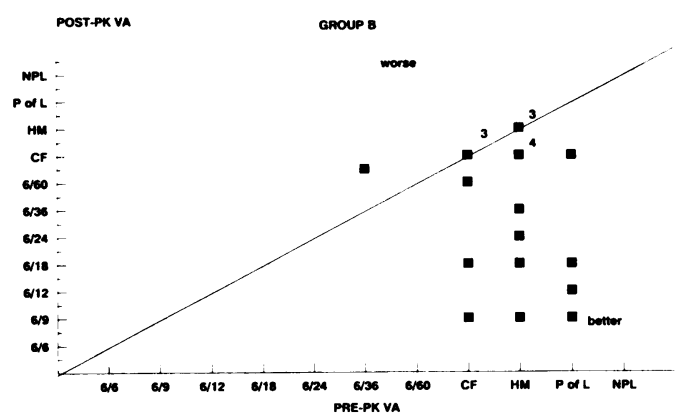

too suggests that there is some advantage in the combined procedure.

\section{Discussion}

The coexistence of glaucoma and corneal disease can result in severe limitation of vision. The accepted approach for visual rehabilitation recommends controlling the pressure before proceeding to keratoplasty. Until the present study no data existed as to the likely outcome of such an approach. Eyes with this combination of disease represent a serious challenge to both surgeon and patient alike. The success of this surgery needs to be assessed in three main areas, namely intraocular pressure control, graft clarity, and recovery of visual acuity.

\section{INTRAOCULAR PRESSURE}

One of the most important determinants of success of drainage surgery is the degree of fibrosis which develops in the bleb. Hitchings and coworkers have clearly established that prolonged topical antiglaucoma therapy may have a deleterious effect on bleb formation by enhancing conjunctival fibrosis. ${ }^{25}$ They also showed that eyes in which there is established conjunctival scarring are also recognised as having a reduced prognosis for successful IOP control. ${ }^{2627}$ Cataract extraction through a standard limbal approach inevitably leads to conjunctival scarring. On this basis all the eyes in this series might be considered as being poor risks for filtration surgery since they had been on long term topical therapy, had scarring from previous ocular surgery, or ocular surface disease. This is further substantiated by the fact that several of the eyes required additional antiglaucoma medication by the time keratoplasty was undertaken in group $A$ in a mean of under 3 years. Conjunctival scarring is probably the most potent reason for poor pressure control in both groups in this series.

Most of the surgery described here predated the experimental use of 5-fluorouracil to reduce bleb fibrosis. Its use however in non-grafted patients indicates that loss of corneal epithelium is an important side effect. ${ }^{28}$ Such an occurrence could have serious implications for graft survival and to our knowledge no series has been reported using this drug in the presence of corneal grafts.

Gross et $a l^{29}$ showed that the aphakic eye per se may also have a reduced prognosis for IOP control. Earlier Bellows and Johnston ${ }^{30}$ presented data from trabeculectomy for glaucoma in aphakia from which it is possible to derive survival curves. These indicate a survival proportion for the maintenance of IOP control at 5 years of $37 \%$. This is very similar to the present data in both groups.

In group $\mathrm{A}$ the major factor common to most failures was a repeat trabeculectomy. Seven out of eight eyes which had had repeat trabeculectomy failed compared with only five out of 18 in which there was only one drainage procedure, a difference which appears highly relevant with a relative risk of 3.2 and $95 \%$ confidence of 1.4 6.9. These data would suggest that should a trabeculectomy have failed in the presence of 
corneal disease, repeat trabeculectomy is unlikely to control the IOP when a corneal graft is undertaken. Silicone drainage tubing may offer a better prospect of success. Kirkness et $a l^{23} 31$ and McDonnell et $a l^{32}$ have shown encouraging results for the control of glaucoma associated with keratoplasty by the use of silicone drainage tubing of various designs. In group B it is curious however that repeat trabeculectomy combined with keratoplasty did not appear to have an adverse prognosis.

It is difficult to explain why the keratoplasty should be associated with deterioration of IOP control but several suggestions can be made. The increased inflammation developing following surgery in these eyes (which have had a mean of 2.6 previous intraocular procedures) might predispose to both increased bleb fibrosis and the development of peripheral anterior synechiae.

The mechanisms involved in the development of post-keratoplasty glaucoma may be relevant to the mechanisms of loss of IOP control in both groups A and B. Olson and Kaufman ${ }^{7}$ have suggested that the combination of aphakia and keratoplasty allows trabecular collapse which reduces outflow. Much of the mathematical background of this work depends upon graft host bed disparity. All the surgeons involved in the present series pay particular attention to graft sizing and all of the donor buttons used were measured to be at least as big if not bigger than host bed. Nevertheless the possibility of trabecular collapse as one component cannot be ruled out entirely. While there has been considerable discussion as to the mechanisms involved in the development of post-keratoplasty glaucoma there is only a little support for the view that at least part of the problem relates to the formation of fine peripheral anterior synechiae closing the angle $^{33}$ which is neither widely reported nor well documented in most series. The patients in this study are a closely related group. Many already had extensive peripheral anterior synechiae. Since peripheral anterior synechiae were so common it was not possible to highlight it as an additional risk factor for loss of IOP control but it is clearly a strong association for these forms of secondary glaucoma. Because of the difficulty in assessing peripheral anterior synechiae through opaque corneas it is also not possible to comment on whether peripheral anterior synechiae tended to increase following keratoplasty predisposing to loss of IOP control.

GRAFT SURVIVAL

The survival of corneal grafts is slightly better in group B than those in the series reported by Gilvarry $e t \mathrm{al}^{34}$ where glaucoma becoming uncontrolled after keratoplasty was managed by trabeculectomy. Gilvarry's series did however contain a higher proportion of repeat keratoplasties which are known to have a poorer prognosis. The nature of eye disease was similar in both series - as might be expected since the common aetiological factors for the development of post-keratoplasty glaucoma are well recognised. The survival of grafts in group B is similar to graft survival in aphakic bullous keratopathy in general ${ }^{35}$ and reflects the most common indication for keratoplasty in the group.

The survival of grafts in group A was very similar to Gilvarry's series. Also similar to Gilvarry et al was the high proportion in both groups $A$ and $B$ failing to be controlled by drainage surgery alone and the need for additional anti-glaucoma medication. In both groups the addition of medication was sufficient to control IOP in the majority of cases. Those failing and requiring further drainage surgery trabeculectomy or silicone drainage surgery did so relatively soon after following graft surgery.

\section{VISUAL ACUITY}

Visual improvement was similar between both groups. Approximately $15 \%$ obtained a corrected acuity of $6 / 12$ or better, and two thirds in both groups showed visual improvement of at least one line of Snellen acuity. The reasons for poor acuity were often multifactorial although the presence of pre-existing glaucoma was often pertinent. These eyes do present complex problems and recovery of normal vision would not be expected in many.

\section{Summary}

The majority of eyes in the two groups reported have the common feature of anterior segment disorganisation involving particularly the cornea and drainage angle. They also appear to behave in a similar fashion to eyes which develop postkeratoplasty glaucoma and have many physical findings in common.

The disappointing results for both pressure control and graft survival when viewed in conjunction with the additional complications suggest that drainage surgery followed by penetrating keratoplasty may not be an ideal way to manage combined corneal disease and glaucoma. Where the vision is good in the fellow eye careful patient selection may limit the extent of the problem but individual cases will remain at risk. Comparison with group $\mathrm{A}$ indicates that combined drainage surgery and keratoplasty offers a better management option for patients with coexisting glaucoma and corneal disease. The combined approach also offers a quicker visual rehabilitation.

Where keratoplasty is deemed worthwhile consideration should be given to either a combined approach of trabeculectomy and keratoplasty or to the use of silicone drainage tubing where there is obvious conjunctival disorganisation. It is self evident that both surgeon and patient should understand the prognosis when embarking on such surgery.

1 Irvine AR, Kaufman HE. Intraocular pressure following penetrating keratoplasty. Am $\mathcal{F}$ Ophthalmol 1969; 68: 83544.

2 Wood TO, West C, Kaufman HE. Control of intraocular pressure in penetrating keratoplasty. Am $\mathcal{f}$ Ophthalmol 1972; 74: 724-8.

3 Olson RJ, Kaufman HE. Prognostic factors after aphakic keratoplasty. Am f Ophthalmol 1978; 86: 510-5.

4 Thoft RA, Gordon JM, Dohlman CH. Glaucoma following keratoplasty. Trans Am Acad Ophthalmol 1974; 78: 352-65. 5 Goldberg DB, Schanzlin DJ, Brown SI. Incidence of increased intraocular pressure after keratoplasty. Am $\mathcal{F}$ Ophthalmol 1981; 92: 372-7.

6 Olson RJ, Zimmerman TJ, Kaufman HE. Elevated intradisease and prevention. Ann Ophthalmol 1978; 10: 931-2. 
7 Olson RJ, Kaufman HE. A mathematical description of causative factors and prevention of elevated intraocular pressure after keratoplasty. Invest Ophthalmol Vis Sci 1977; 16: 1085-92.

8 Zimmerman TJ, Krupin T, Gordzki Q, Waltman SR, Kaufman HE. Size of donor corneal buttons and outflow facility in aphakic eyes. Ann Ophthalmol 1979; 11: 809-11.

9 Olson RJ. Aphakic keratoplasty. Determining donor tissue size to avoid elevated intraocular pressure. Arch Ophthalmol 1978; 96: 2274-6.

10 Zimmerman T, Olson R, Waltman S, Kaufman H. Transplant size and elevated intraocular pressure. Ophthalmology 1978; 96: 2231-3

11 Foulks GN, Perry HD, Dohlman CH. Oversize corneal donor grafts in penetrating keratoplasty. Ophthalmology 1979; 86: 490-4.

12 Perl T, Charlton KH, Binder PS. Disparate diameter grafting, astigmatism, intraocular pressure and visual acuity. Ophthalmology 1981; 88: 774-81.

13 Bourne WM, Davison JA, O'Fallon WM. The effects of oversize donor buttons on postoperative intraocular pressure and corneal curvature phakic penetrating keratoplasty. Ophthalmology 1982; 89: 242-6.

14 Foulks GN. Glaucoma associated with penetrating keratoplasty. Ophthalmology 1987; 94: 871-4.

15 van Meter WS, Allen RC, Waring III GO, Stulting RD. Laser trabeculoplasty for glaucoma in aphakic and pseudophakic eyes after penetrating keratoplasty. Arch Ophthalmol 1988; 106: 185-8

16 Karesh JW, Nirankari VS. Factors associated with glaucoma after penetrating keratoplasty. Am $\mathcal{F}$ Ophthalmol 1983; 96: $160-4$.

17 Kirkness CM, Moshegov C. Post-keratoplasty glaucoma. Eye 1988; 2 (suppl): S19-26.

18 Coster DJ. Mechanisms of corneal graft failure: the erosion of corneal privilege. Eye $1989 ; 2$ : 251-62.

19 Waltman SR. Penetrating keratoplasty. In: Waltman SR, Keates RH, Hoyt CS, Frueh BP, Herscher J, Carol DM, eds. Surgery of the eye. New York: Churchill Livingstone, 1988: 193-216.

20 Williamson TH, Bacon AS, Flanagan DW, Jakeman CM, Jordan K. Combined extracapsular cataract extraction and trabeculectomy using a separated corneal section. Eye 1989; 3: $547-52$.

21 Insler MS, Cooper HD, Kastl PR, Caldwell DR. Penetrating keratoplasty with trabeculectomy. Am $\mathcal{F}$ Ophthalmol 1985;
100: 593-5.
22 Barraquer J, Garcia-Barberan I, Ingelsisas E, et al. Triple procedure: Penetrating keratoplasty, trabeculectomy and cataract extraction. Dev Ophthalmol (Basel) 1989; 18: $142-5$.

23 Kirkness CM, Ling Y, Rice NSC. The use of silicone drainage tubing to control post-keratoplasty glaucoma. Eye 1988; 2: 583-90.

24 Machin D, Gardener MJ. Calculating confidence intervals for survival time analyses. In: Gardner MJ, Altman DG, eds. Statistics with confidence. London: British Medical Journal, 1989; chap 6: 64-70.

25 Hitchings RA, Grierson I. Clinicopathological correlation in eyes with failed fistulising surgery. Arch Ophthalmol 1988; 103: 85-8.

26 Joseph JP, Miller MH, Hitchings RA. Wound healing as a barrier to successful filtration surgery. Eye 1988; 2 (suppl): S113-23.

27 Miller MH, Joseph JP, Wishart PK, Hitchings RA. Lack of beneficial effect of intensive topical steroids and beta radiation of eyes undergoing repeat trabeculectomy. Ophthalmic Surg 1987; 18: 508-12.

28 The Fluorouracil Filtering Surgery Study Group. Fluorouracil filtering study, one year follow-up. Am $\mathcal{F}$ Ophthalmol 1989; filtering study

29 Gross RL, Feldman RM, Spaeth GL, Steinmann WC, Speigel $\mathrm{D}$, Katz LJ, et al. Surgical therapy of chronic glaucoma in
aphakia and pseudophakia. Ophthalmology 1988; 95: 1195201 .

30 Bellows AR, Johnston MA. Surgical management of chronic glaucoma in aphakia. Ophthalmology 1983; 90: 807-13.

31 Kirkness CM. Penetrating keratoplasty, glaucoma and silicone drainage tubing. Dev Ophthalmol 1987; 14: 161-5.

32 McDonnell PJ, Robin JB, Schanzlin DJ, Minckler D, Bacrveldt G, Smith RE, et al. Molteno implant for control of glaucoma in eyes after penetrating keratoplasty. Ophthalmology 1988; 95: 364-9.

33 Lass JH, Pavan-Langston D. Timolol therapy in secondary angle-closure glaucoma post penetrating keratoplasty. Ophthalmology 1979; 86: 51-9.

34 Gilvarry AME, Kirkness CM, Steele ADMcG, Rice NSC, Ficker LA. The management of post-keratoplasty glaucoma Ficker LA. The management of post-ke

35 Yap EY, Garana R, Kirkness CM, Ficker LA, Steele ADMcG, Rice NSC. Penetrating keratoplasty in the bullous keratopathies. Proceedings of the XXVI International Congress of Ophthalmology, Elsevier, Amsterdam (in press). 